\title{
Development of Models of Optimal Investment Strategies
}

\author{
Galina Zhukova ${ }^{1, *}$ Dinara Kagirova ${ }^{2}$
}

\author{
${ }^{1}$ Financial University under the Government of the Russian Federation, 49, Leningradskiy Avenue, Moscow, 125993, \\ Russian Federation \\ ${ }^{2}$ Moscow Polytechnic University, 38, B. Semenovskaya str., Moscow, 107023, Russian Federation \\ *Corresponding author. Email: galsevzhukova@mail.ru
}

\begin{abstract}
The aim of the study is to model the stochastic average annual return on the investment portfolio of pension savings for various combinations of asset weights over a 40-year horizon, with an assessment of the risk level for each combination. To estimate the loss of portfolio VaR, an approach that combines copula functions, extreme value theory (EVT) and GARCH models is used. The main results obtained are the following: the average annual return and risk levels of the conservative and expanded portfolios of Vnesheconombank of Russia over the long-term investment period are predicted; a comparative analysis of the impact on the portfolio of legislative restrictions on the assets of the portfolio of pension savings and restrictions on the portfolio VaR; optimal strategies have been selected to achieve a level of pension provision that meets international standards, with a minimum risk. The results of the study and the optimization procedure proposed in the work can be applied in the field of asset management and risk management.
\end{abstract}

Keywords: investment portfolio optimization, extreme value method, copula, generalized Pareto distribution,

Monte Carlo, pension savings, VaR, GARCH

\section{INTRODUCTION}

Currently, the Russian pension system is characterized by an indicator of lost earnings below the standards established by the International Labor Organization. The increase in the retirement age since 2019 is justified and we meet the new demographic realities. However, the growing budget deficit of the Pension Fund of the Russian Federation and the demographic load factor lead to the failure of the insurance pension system to ensure the pension rights of citizens at the level of international standards. At the same time, the investment return on pension savings over the past few years has remained quite low, did not cover inflation, despite the Decree of the President of the Russian Federation of May 7, 2018 "On national goals and strategic objectives of the development of the Russian Federation for the period until 2024" [1 ]. As a result, the Government of the Russian Federation temporarily suspended the formation of a funded pension for citizens. It should also be noted that, unlike the insurance and banking sectors, the Russian pension sector does not have a unified system of risk management standards similar to Basel and Solvency.

When comparing the Russian pension system with effective foreign pension systems, it can be noted that the Russian system is characterized by too severe restrictions on the composition of the portfolio of pension savings and the imperfection of the risk management system in the pension sector.
Thus, the insufficient efficiency of managing pension savings funds and a weak risk management system in the pension sector determine the relevance of the study on portfolio management in funded pension plans.

Many researchers have studied the risk management of various portfolios, for example, [2-15]. One of the most popular indicators for measuring the total risk of a portfolio of financial assets is Value-at-Risk ( $\mathrm{VaR})$.

$\mathrm{VaR}$ is an estimate of the amount of losses measured in the base currency, which with a given probability will not exceed the loss of the investment portfolio over a given period.

The aim of this study is to model the stochastic average annual return on an investment portfolio of pension savings for various combinations of asset weights over a 40-year time horizon, with an assessment of the risk level for each combination. To evaluate the VaR portfolio, an approach is used that combines copula functions, extreme value theory (EVT) and GARCH models. To develop optimal investment strategies in long-term funded pension plans, the GARCH-EVT-COPULA approach has been applied [2-3].

\section{DATA AND METHODOLOGY}

\subsection{Data}

In accordance with Article 26 of the Federal Law No. 111FZ "On Investing Funds for Financing a funded pension in 
the Russian Federation", daily benchmark quotes for each type of financial asset from January 01, 2006 to July 01, 2019 were taken as a statistical base (MICEX RGBI TR, MICEX MBI TR, MICEX CBI TR, MICEX 10 INDEX, RURRPRC, CBR deposit rate "overnight", USD / RUB).

Daily price values are transformed into daily returns (except for deposits), and are calculated by the formula [4]:

$$
\begin{aligned}
& \text { (1) } r_{t}=\log \left(1+R_{t}\right) \text {, } \\
& \text { (2) } R_{t}=\frac{s_{t}-s_{t-1}}{s_{t-1}}
\end{aligned}
$$

(Fig. 1).

Overnight interest rates on daily deposits of the Central Bank of the Russian Federation were calculated using the compound interest rate formula taking into account interest capitalization:

$$
r_{\text {day }}=\sqrt[260]{1+r_{\text {year }}}-1
$$

where $\boldsymbol{r}_{\boldsymbol{d a y}}$ - is the daily rate of return, $\boldsymbol{r}_{\text {year }}$ is the annual rate of return, 260 is the average number of working days in a year.

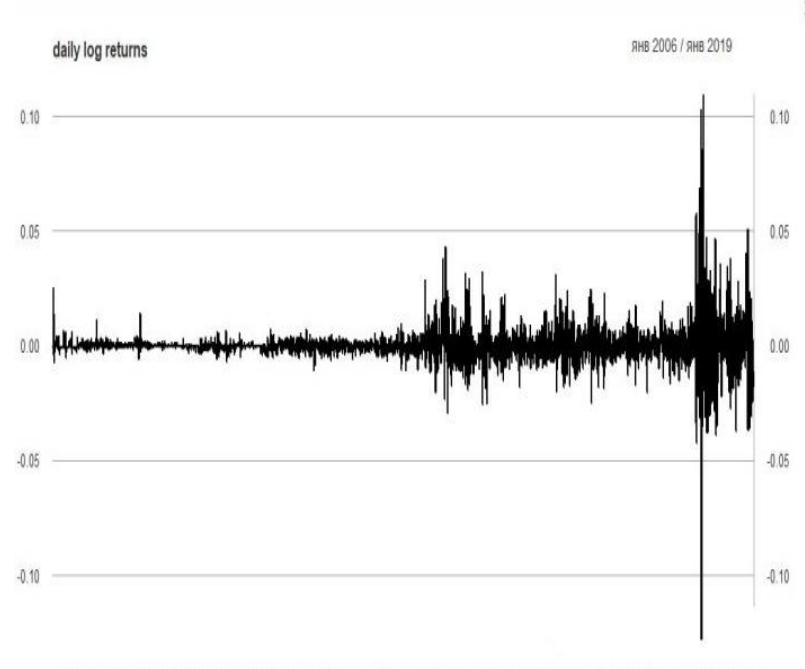

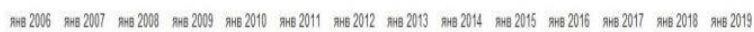

Figure 1 An example of calculating daily returns for an asset USD/RUB

\subsection{Modeling of marginal profitability distributions}

We use GARCH models to model the time series of asset returns. GARCH is based on a regression approach. The conditional average is modeled by the autoregression process with a moving average $\operatorname{ARMA}(p, q)$ :

(4) $\boldsymbol{r}_{s, t}=\boldsymbol{c}_{s, 0}+\sum_{i=1}^{p} \boldsymbol{\phi}_{s, i} \boldsymbol{r}_{s, t-i}+\sum_{j=1}^{q} \theta_{s, j} \boldsymbol{r}_{s, t-j}+\boldsymbol{e}_{s, t}$. where $s$ - tickers (MICEX RGBI TR, MICEX MBI TR, MICEX CBI TR, MICEX 10 INDEX, RURRPRC, CBR deposit rate "overnight", USD / RUB),

$\boldsymbol{c}_{\boldsymbol{s}, \mathbf{0}}$ - constant, $\boldsymbol{\phi}_{s, i}-$ autoregressive coefficients,

$\boldsymbol{\theta}_{s, j}-$ moving average coefficients,

$\boldsymbol{e}_{s, t}-$ white noise.

Random error $\boldsymbol{e}_{\boldsymbol{s}, \boldsymbol{t}}$ can be decomposed into two multiplicative components: the value $\boldsymbol{z}_{\boldsymbol{s}, t}$, with a single variance, and the variance itself $\sqrt{\boldsymbol{h}_{\boldsymbol{s}, \boldsymbol{t}}}$. As a result we get:

(5) $\boldsymbol{e}_{\boldsymbol{s}, \boldsymbol{t}}=\sqrt{\boldsymbol{h}_{s, t}} \boldsymbol{z}_{s, t}$.

Conditional variance $\boldsymbol{h}_{\boldsymbol{s}, \boldsymbol{t}}$ is modeled by $\boldsymbol{G A R C H}(\boldsymbol{p}, \boldsymbol{q})$ process:

(6) $h_{s, t}=\omega_{s}+\sum_{i=1}^{p} \alpha_{s, i} e_{s, t-i}^{2}+\sum_{j=1}^{q} \beta_{s, j} h_{s, t-j}$.

The following notation is used here.:

$\boldsymbol{\alpha}_{\boldsymbol{s}}-\boldsymbol{A R C H}$ coefficients,

$\boldsymbol{\beta}_{s}-\boldsymbol{G A R C H}$ coefficients.

$\boldsymbol{A R M A}(\boldsymbol{p}, \boldsymbol{q})$ model order identification is limited by conditions: $\boldsymbol{p}, \boldsymbol{q} \leq \mathbf{5}$. Optimal order for $\boldsymbol{G A R C H}(\boldsymbol{p}, \boldsymbol{q})$ models is limited by conditions $\boldsymbol{p}, \boldsymbol{q} \leq \mathbf{2}$. Choosing the best model combines a single root test (ADF), minimizing the Akaike criterion (AIC) and maximum likelihood examination (MLE) [5].

An important aspect is the choice of frequency distribution $\boldsymbol{z}_{\boldsymbol{s}, \boldsymbol{t}}$. Since the distribution of time series of financial assets is characterized by thick tails, the Extreme Value Theory (EVT) method is used to model the standardized component.

There are two fundamental approaches to the theory of extreme values - the Block Maximum (BM) method and the Peak Over Threshold (POT) method. The first method has a significant drawback: from the entire array of these assets, the researcher ignores the available observations except for the block maximum [6].

The method of exceeding the threshold value is expressed in approximation of the distribution function of the values of a random variable, the maxima of which converge, to the generalized Pareto Distribution (GPD).

For a random variable, the distribution of excesses of a certain threshold is expressed by the formula:

(7) $F_{i, u_{i}}(x)=P\left(x_{i, t}-u_{i} \leq x \mid x_{i, t}>u_{i}=\right.$

$$
=\frac{F_{i}\left(x+u_{i}\right)-F_{i}\left(u_{i}\right)}{1-F_{i}\left(u_{i}\right)} \text {. }
$$

Then, assuming that this function belongs to the GPD family, we can determine the probability of exceeding the threshold value.

Denote:

(8) $\quad \dot{\boldsymbol{F}}_{\boldsymbol{i}}(\boldsymbol{x})=\mathbf{1}-\boldsymbol{F}_{\boldsymbol{i}}(\boldsymbol{x})$.

Then the desired probabilities are written as follows:

(9) $\boldsymbol{F}_{i}\left(\boldsymbol{x} \mid \boldsymbol{x}_{i, t}>\boldsymbol{u}_{i}=\boldsymbol{P}\left(\boldsymbol{x}_{i, t}>\boldsymbol{u}_{i}\right) \cdot \boldsymbol{P}\left(\boldsymbol{x}_{i, t}>\boldsymbol{x} \mid \boldsymbol{x}_{i, t}>\right.\right.$

$u_{i}=$

$$
\begin{aligned}
& =P\left(x_{i, t}>u_{i}\right) \cdot P\left(x_{i, t}-u_{i}>x-u_{i} \mid x_{i, t}>u_{i}=\right. \\
& =\dot{F}_{i}\left(u_{i}\right) \cdot \dot{F}_{i, u_{i}}\left(x-u_{i}\right)=\dot{F}_{i}\left(u_{i}\right) \cdot\left(1+\frac{\xi\left(x-u_{i}\right)}{\beta}\right)^{\frac{-1}{\xi}},
\end{aligned}
$$

where $u, \beta \& \xi$-parameters of position, scale and form of generalized Pareto distribution.

We use the estimate of the unknown quantity $\boldsymbol{F}_{\boldsymbol{i}}\left(\boldsymbol{u}_{\boldsymbol{i}}\right)$ :

(10) $\hat{\boldsymbol{F}}_{i}(x)=\frac{T_{i, u_{i}}}{T}\left(1+\frac{\hat{\xi}\left(x-u_{i}\right)}{\hat{\beta}}\right)^{\frac{-1}{\xi}}, \quad x \geq u_{i}$, 
where $\boldsymbol{T}_{\boldsymbol{i}, \boldsymbol{u}_{\boldsymbol{i}}}$ is the number of reductions in the balances of the $i$-th asset type, exceeding the value $\boldsymbol{u}_{\boldsymbol{i}}$.

Based on formulas (8) and (9), the balances in the upper and lower tails for pension savings assets (GPD) [7] are calculated by the formula:

(11) $(\mathrm{F}(\mid \boldsymbol{s}, \boldsymbol{t})=$

$$
=\left\{\begin{array}{c}
\frac{N_{m_{L}}}{N}\left(\left(1+\frac{\xi_{L}\left(m_{L}-z_{s, t}\right)}{\beta_{L}}\right)^{\frac{-1}{\xi_{L}}}\right), \\
z_{s, t}<m_{L}, \\
\varphi\left(z_{s, t}\right), \quad m_{L}<z_{s, t}<m_{R}, \\
1-\frac{N_{m_{R}}}{N}\left(\left(1+\frac{\xi_{R}\left(m_{R}-z_{s, t}\right)}{\beta_{R}}\right)^{\frac{-1}{\xi_{R}}}\right. \\
z_{s, t}>m_{R} .
\end{array}\right),
$$

Here $\xi$ - the form parameter, $\beta$ - the scale parameter, $m_{L}\left(m_{R}\right)$ - the position parameter.

The optimal threshold value is 10 percentiles.

\subsection{Modeling of joint distribution using copula functions}

Let us remind that formally, a copula is a strictly increasing function of several variables with a definition domain $[\mathbf{0} ; \mathbf{1}]^{n}$ and a range of values $[0 ; 1]$. Transforming $C:[\mathbf{0 , 1}]^{n} \rightarrow[\mathbf{0 , 1}]$ takes a point of $n$-dimensional space to a point on the segment $[0 ; 1]$ of the number line.

Copulas are used to build a common multidimensional distribution $\boldsymbol{F}_{\boldsymbol{x}}(\boldsymbol{x})$ based on the knowledge of marginal distributions $\boldsymbol{F}_{\boldsymbol{x}_{\boldsymbol{i}}}\left(\boldsymbol{x}_{\boldsymbol{i}}\right)$.

This result is based on the following Shklyar theorem [8]: пусть $\boldsymbol{F}_{\xi_{1}}\left(\boldsymbol{x}_{\mathbf{1}}\right), \ldots, \boldsymbol{F}_{\xi_{d}}\left(\boldsymbol{x}_{\boldsymbol{d}}\right)$ - continuous distribution functions of some random variables $\xi_{1}, \ldots, \xi_{\boldsymbol{d}}, \boldsymbol{H}_{\xi_{1} \ldots \xi_{d}}(\boldsymbol{x})$ - their joint distribution function, $\dot{x}=\left(\boldsymbol{x}_{1}, \ldots, \boldsymbol{x}_{\boldsymbol{d}}\right)$, copula $\boldsymbol{C}\left(\boldsymbol{u}_{\boldsymbol{i}}, \ldots, \boldsymbol{u}_{\boldsymbol{d}}\right)$ is such that

$$
\text { (12) } C\left(F_{\xi_{1}}\left(x_{1}\right), \ldots, F_{\xi_{d}}\left(x_{d}\right)\right)=H_{\xi_{1} \ldots \xi_{d}}\left(x_{1}, \ldots, x_{d}\right) \text {. }
$$

On the other side with the set distributions $\boldsymbol{F}_{\xi_{i}}\left(\boldsymbol{x}_{\boldsymbol{i}}\right), \boldsymbol{i} \in$ $\{\mathbf{1} ; \ldots ; \boldsymbol{d}\}$, and copula $\boldsymbol{C}\left(\boldsymbol{u}_{\boldsymbol{i}}, \ldots, \boldsymbol{u}_{\boldsymbol{d}}\right)$ function $\boldsymbol{H}_{\xi_{1} \ldots \xi_{d}}\left(\boldsymbol{x}_{1}, \ldots, \boldsymbol{x}_{\boldsymbol{d}}\right)$, obtained by private distributions in the copula will be a joint distribution function of quantities $\xi_{1}, \ldots, \xi_{d}$.

Thus, Shklar's theorem allows dividing the procedure for estimating the parameters of a multidimensional distribution into several stages:

1. The choice of families of distribution functions $\boldsymbol{F}_{\xi_{\boldsymbol{i}}}\left(\boldsymbol{x}_{\boldsymbol{i}}\right)$;

2. Estimation of parameters of selected functions;

3. Choosing a copula family $\boldsymbol{C}\left(\boldsymbol{F}_{\xi_{1}}\left(\boldsymbol{x}_{\mathbf{1}}\right), \ldots, \boldsymbol{F}_{\xi_{d}}\left(\boldsymbol{x}_{\boldsymbol{d}}\right)\right)$;

4. Estimation of the selected copula function parameters.

Such separation into stages allows, firstly, to generalize the traditional approach to modeling the joint distribution function due to the possibility of using various, most suitable, private distribution functions. Secondly, the copula, being insensitive to monotonous transformations, allows modeling a nonlinear relationship between components of assets [8]. A non-linear relationship is characteristic of returns on financial assets, as shown in [9-13]. The authors point out the shortcomings of the linear correlation coefficient for assessing the relation of random variables that obviously do not have a normal distribution

Elliptical copulas are built on the basis of multidimensional distribution functions. The elliptic class includes Gauss copula (normal), and Student's. They are most often used to analyze financial data. [14]

Student's copula is written as follows:

$$
\begin{aligned}
& t_{v}^{-1}\left(u_{1}\right), \ldots, t_{v}^{-1}\left(u_{d}\right), \\
& C_{T}\left(u_{i}, \ldots, u_{d}\right)=t_{P, v},
\end{aligned}
$$

where $\boldsymbol{t}_{\boldsymbol{P}, \boldsymbol{v}}$ (.) $-d$-dimensional Student distribution with $\boldsymbol{v}$ degrees of freedom and correlation matrix $\boldsymbol{P} ; \boldsymbol{t}_{v}()-$. Student's one-dimensional distribution.

Student's copula parameters are the coefficients of the correlation matrix and the number of degrees of freedom.

\subsection{The optimal portfolio of the pension savings}

Summarizing the above, we can propose the following algorithm for modeling the profitability of pension fund portfolios:

1. Currently, marginal asset allocations are calculated;

2. The current rank correlation matrix of stock indices is calculated;

3. Using a copula, a joint distribution is built and 10,000 Monte Carlo simulations are performed (simulations allow obtaining profitability scenarios);

4. The Monte Carlo method determines the expected return of each asset and its risk assessment by the value of the VaR coefficient.

\section{RESULTS}

\subsection{Modeling pension fund investment portfolios without considering asset restrictions}

An individual's working experience before retirement is 40 years on average, and an average of 260 working days is expected each year. So, we get 7,800 asset modeling steps [15].

According to the Federal Law No. 111 dated July 24, 2002 "On investing funds to finance the funded part of the labor pension in the Russian Federation," the State Management Company, whose functions are currently performed by Vnesheconombank (VEB), invests pension savings of citizens in two investment portfolios: conservative investment portfolio (government securities portfolio); extended investment portfolio.

The conservative portfolio of Vnesheconombank includes: 


\subsection{Modeling pension fund investment portfolios with an account of asset restrictions} make up $47.30 \%$ of the portfolio;

- Bonds of Russian issuers guaranteed by the Russian Federation $-52.70 \%$ of the portfolio.

The structure of the expanded portfolio of Vnesheconombank includes assets:

- Government securities of the Russian Federation, comprising $39.80 \%$ of this portfolio;

- Bonds of Russian issuers - $41.75 \%$;

- Bank deposits in rubles $-13.90 \%$;

- Mortgage securities - $3.15 \%$;

- Bonds of international financial organizations $-1.40 \%$.

As a result of the simulation, an empirical distribution function of the average annual return of each portfolio of pension savings over a 40-year time horizon was obtained (Fig. 2).

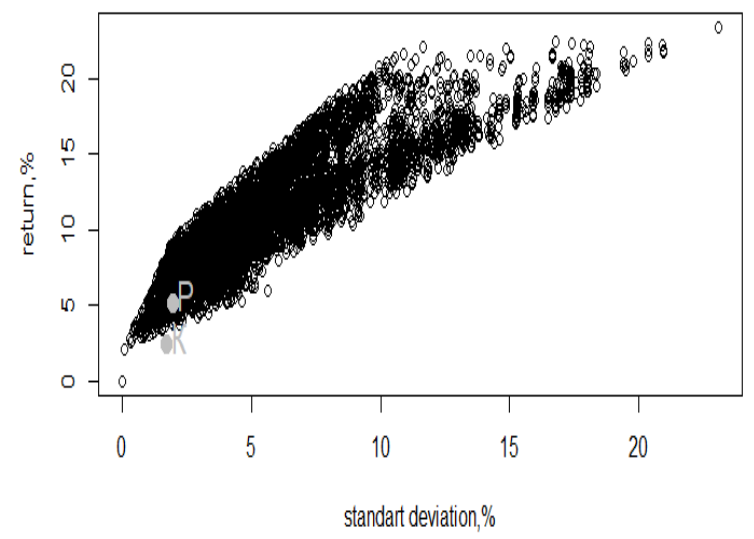

Figure 2 Portfolio set in the absence of restrictions

The ordinate axis measures the average annual return on portfolios in percent, the abscissa axis shows the standard deviation of the average annual return. Gray dots indicate the expanded (P) and conservative $(\mathrm{K})$ portfolios of Vnesheconombank.

The calculations showed that both portfolios lie significantly below the effective border of the portfolios (according to Markowitz theory). Therefore, both portfolios are not optimal. So, there are other portfolios that provide greater returns at the same risk level.

It turned out that the return on the conservative (K) investment portfolio of Vnesheconombank of the Russian Federation amounted to $3.27 \%$ with a risk level of $1.23 \%$. This value is lower than the current inflation rate in the Russian Federation (for example, annual inflation by the beginning of 2019 was $3.9 \%$ ).

Vnesheconombank's extended (P) investment portfolio showed the best results: its average annual return was $5.11 \%$ with the same risk level of $1.23 \%$.

Thus, when choosing between Vnesheconombank's expanded $(\mathrm{P})$ and conservative $(\mathrm{K})$ portfolios of the State Management Company, it is advisable, in our opinion, to give preference to an expanded investment portfolio.
According to the legislation of the Russian Federation, the maximum shares of assets in the portfolio of pension savings formed from funds transferred by the Pension Fund of the Russian Federation to the trust management of the management company are:

- Government securities of the Russian Federation - up to $100 \%$;

- Government securities of constituent entities of the Russian Federation - up to $40 \%$;

- Bonds of Russian issuers (except OFZ and municipal) up to $80 \%$;

- Shares of Russian issuers (OJSC) - up to 65\%;

- Mortgage securities - up to $40 \%$;

- Deposits in the currency of the Russian Federation - up to $80 \%$;

- Foreign currency.

Below in fig. 3 gray color indicates investment portfolios with legislative restrictions on assets, black - unlimited portfolios

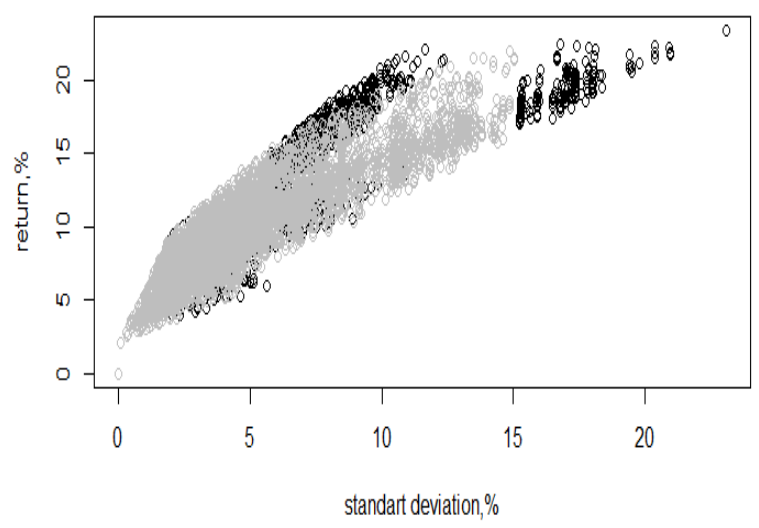

Figure 3 Portfolio with legislative restrictions on assets

The presented results show that legislative restrictions on the maximum shares of assets in the portfolio make it possible to abandon high-risk portfolios located (in Fig. 3) in the right tail of the distribution. However, they crop part of the effective boundary of the portfolio set (portfolios lying above the gray cloud).

Thus, following the legislative restrictions on assets, the management company is forced to abandon portfolios that could potentially bring greater returns at the same risk level.

\subsection{Modeling pension fund investment portfolios with restrictions on portfolio risk level based on the VaR value}

Let us analyze the case when there are no legislative restrictions on assets, but restrictions on the value of VaR of the portfolio (Fig. 4).

Fig. 4 illustrates the situation when the restrictions on the 
VaR with a maximum value of $1 \%$ portfolio are set at $2.5 \%$.

The choice of calculation period, significance level and maximum VaR value were made by analogy with the Mexican risk management system that has already been functioning and has successfully proved itself in the funded pension system.

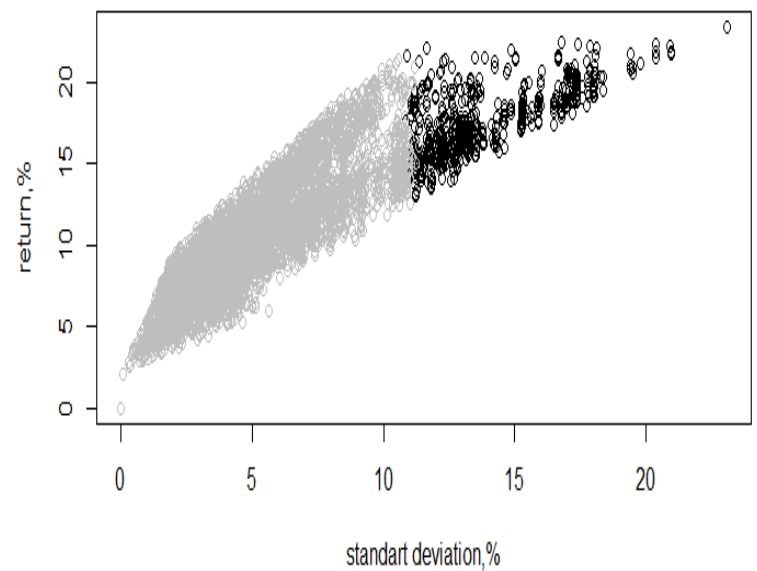

Figure 4 Portfolio set with restrictions on the VaR value of $2.5 \%$

In fig. 4 we observe that the restrictions on the value of the portfolio $\mathrm{VaR}$ cut off only the right tail of the portfolio distribution - the riskiest portfolios.

Thus, restrictions on the VaR of the portfolio allow the management company to form more profitable portfolios than under legislative restrictions on assets, while maintaining the same level of risk.

Consider less conservative restrictions on the portfolio risk level - VaR with a maximum value of $1 \%$.

In fig. 5 we see that by limiting the $\mathrm{VaR}$ of the portfolio by only $1 \%$ (black), it is possible to expand up the many available portfolios of pension savings in comparison with Fig. 4, where VaR limits were $2.5 \%$.

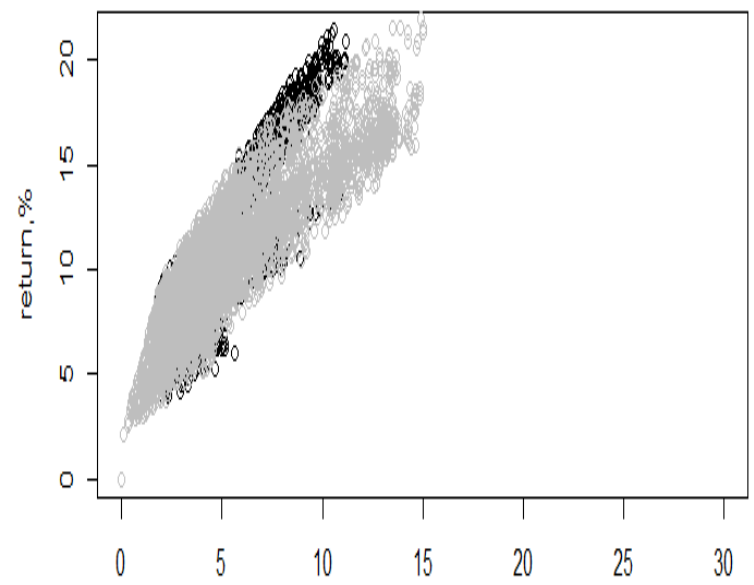

standart deviation, \%

Figure 5 Portfolio set with restrictions on the value of
Comparing the situations observed in fig. 4 and fig. 5, we note that the $2.5 \% \mathrm{VaR}$ rating restrictions cut off a smaller part of the right tail of the investment portfolio distribution (only the most risky portfolios), compared to the $1 \%$ VaR restrictions.

Thus, we can conclude that the restrictions on VaR of $1 \%$ are optimal (preferred) under the conditions of the problem under study

\subsection{Modeling the replacement rate of lost earnings. Choosing the optimal investment strategies}

The pension replacement ratio for lost earnings is the ratio of the pension to the last wage. In international practice, this coefficient is used as the main indicator of the pensioners' level of well-being and the effectiveness of the pension system as a whole.

To model the replacement rate of lost earnings by the pension, assets are used that allow to achieve the optimal value of the coefficient established by international standards. The optimal value of the coefficient is achieved by including assets with a minimum standard deviation (with a minimum level of risk) into the model.

To model the target rate of return on pension savings, we analyze the monthly contributions of an employee with 40 years of experience.

According to the chapter "Insurance Contributions" of the Tax Code of the Russian Federation, the amount of contributions for compulsory pension insurance is $22 \%$ of the wage fund. Of these, $16 \%$ go to the formation of an insurance pension, $6 \%$, at the choice of the employee, can go to the formation of a funded or insurance pension. At the moment, the Government of the Russian Federation has introduced a temporary restriction on the formation of a funded pension to stabilize the budget of the Pension Fund of the Russian Federation.

According to the Federal State Statistics Service of the Russian Federation, the average monthly nominal accrued salary of employees in a full range of organizations in the constituent entities of the Russian Federation in 2019 amounted to 49347.90 rubles.

According to a moderately optimistic scenario for the long-term forecast of socio-economic development of Russia, developed by the Ministry of Economic Development of the Russian Federation, the average annual nominal wage growth rate of $7.3 \%$ will be observed over the long term. The inflation rate following the longterm forecast of the Ministry of Economic Development is assumed to be $4 \%$.

By article 7 of the Federal Law of December 28, 2013 No. 424-FZ "On funded pension", the amount of funded pension is calculated by the formula:

$$
\mathrm{NP}=\frac{\mathrm{PN}}{\mathrm{T}},
$$


where NP is the amount of the funded pension, $\mathrm{PN}$ is the amount of pension savings, $\mathrm{T}$ is the number of months of the expected period of the funded pension.

For 2020, its size is set equal to 258 months (in accordance with the document dated December 27, 2019 No. 446-Ф3 "On the Expected Period of Payment of the Accumulative Pension for 2020").

The calculation of the replacement rate of lost earnings is calculated by the formula:

$$
\mathrm{K}=\frac{\mathrm{NP}}{\mathrm{ZP}_{40}},
$$

where $\mathrm{K}$ is the replacement rate for lost earnings, NP is the funded pension, $\mathrm{ZP}_{40}$ is the salary for the 40th year of investment.

Based on international standards (Convention of the International Labor Organization No. 102 "On Minimum Standards of Social Security"), a replacement rate of $40 \%$ was chosen as the target level of profitability of pension savings.

Fig. 6 shows the distribution of lost earnings ratios with restrictions on the portfolio VaR.

On the ordinate axis is the replacement rate for lost earnings (in\%). The abscissa indicates the measure of risk (standard deviation of the coefficient of lost earnings). The horizontal line marks the target level of the replacement coefficient - a measure of profitability (median of the resulting distribution of coefficients).
Thus, when modeling the distribution of lost earnings coefficients under $\mathrm{VaR}$ restrictions, a significant part of the portfolios are above the median value.

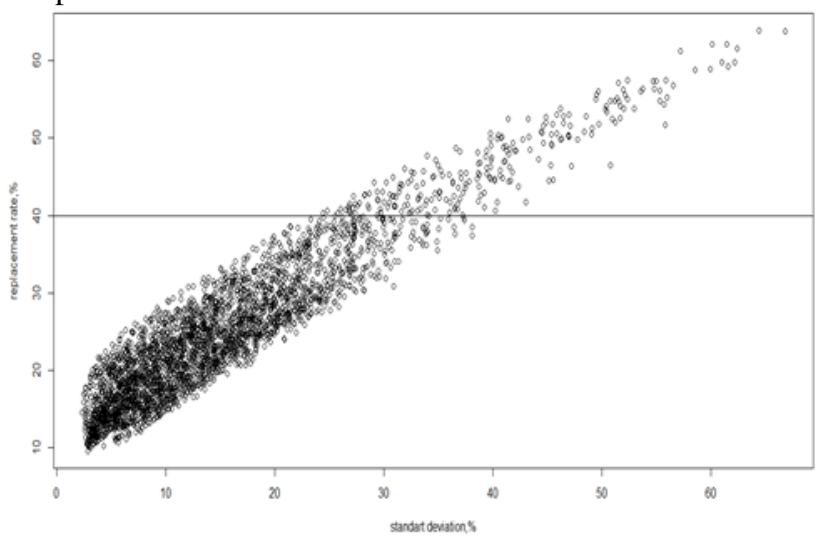

Figure 6 Distribution of replacement rates for lost earnings with restrictions on $\mathrm{VaR}$

Among these portfolios, we highlight:

4 optimal portfolios that provide a target level of profitability with a minimum level of risk (standard deviation is $25-26 \%$ ), 11 portfolios with a standard deviation of $27-28 \%$. The summary characteristics of these portfolios are presented in table 1 .

Table 1 Summary characteristics of investment portfolios

\begin{tabular}{|c|c|c|c|c|c|c|}
\hline RGBI & MBI & CBI & MICEX 10 INDEX & RURRPRC & Deposits & USD/RUB \\
\hline $3-5 \%$ & $1-2 \%$ & $3-5 \%$ & $10-15 \%$ & $49-56 \%$ & $20-30 \%$ & $5-10 \%$ \\
\hline $20-30 \%$ & $3-5 \%$ & $3-5 \%$ & $10-15 \%$ & $40-50 \%$ & $3-5 \%$ & $10-15 \%$ \\
\hline
\end{tabular}

Thus, the maximum share of the optimal portfolio should be mortgage-backed securities, since they are characterized by lower volatility than stocks, but at the same time have a relatively high yield, which allows reaching the target level of the replacement ratio.

Risks on mortgage-backed securities are diversified due to the inclusion in the portfolio of a large share of government bonds or deposits (20-30\%). In case of risk reduction due to government bonds, we increase the share of foreign currency in the portfolio to $10-15 \%$, since it has a rather high negative correlation with government securities.

The share of municipal and corporate bonds in the portfolio remains very low due to the low yield of these bonds.

The share of shares in the portfolio is $10-15 \%$, which allows us to increase the profitability of the portfolio and contributes to greater diversification of risks.

An alternative investment option involves increasing the share of shares to $20 \%$ while maintaining the share of mortgage-backed securities at $40 \%$. The shares of the remaining assets in the portfolio are retained. This investment option allows you to achieve a higher level of profitability, but it is associated with greater risks.

\section{CONCLUSION}

The analysis of the problems and tasks of the Russian pension system was carried out in the presented work. To this end, the stochastic average annual return on the investment portfolio of pension savings was simulated for various combinations of asset weights over a 40-year time horizon, while obtaining risk level estimates for each combination. To estimate the loss of portfolio $\mathrm{VaR}$, an approach that combines copula functions, extreme value theory (EVT) and GARCH models was used. The average annual profitability and risk levels of the conservative and expanded portfolios of Vnesheconombank of Russia are forecasted over a long-term investment period; a comparative analysis of the impact on the portfolio of legislative restrictions on the assets of the portfolio of pension savings and restrictions on the portfolio VaR; optimal strategies have been selected to achieve a level of pension provision that meets international standards, with a minimum level of risk. The replacement rate for lost earnings is modeled. The scheme for choosing optimal investment strategies is proposed. 
[6] J.-J. Huang, K.-J. Lee, H. Liang, W.-F. Lin. Estimating value at risk of portfolio by conditional copula-GARCH method, Insurance: Mathematics \& Economics. Vol. 45. 2009, № 3. P. 315-324.

[7] Z.-R. Wang, X.-H. Chen, Y.-B. Jin, Y.-J. Zhou. Estimating risk of foreign exchange portfolio: using VaR and CVaR based on GARCH-EVT-Copula model, A: Statistical Mechanics and Its Applications. Vol. 389. 2010, № 21. P. 4918-4928.

[8] R. K. Y. Low, J. Alcock, R. Faff, T. Brailsford. Canonical vine copulas in the context of modern portfolio management: are they worth it?, Journal of Banking and Finance. Vol. 37. 2013, № 8. P. 3085-3099.

[9] E. Popovskaya, N. Rozanova, G. Zhukova. On market surveys as a tool for forecasting the economic situation // Voprosy Ekonomiki. 2004. No. 5. P. 111-120.

[10] G. S. Zhukova. Prediction of the investment process in relation to the conditions of transformation and integration into the international financial system // Research notes of the Russian State Social University. Vol. 2. 2013. № 5 (120) P. 140-145.

[11] G. S. Zhukova, D. R. Kagirova. Structural changes in the global economy: non-traditional correlation analysis, In the collection: Modern trends in the development of science and education: Theory and Practice Materials of the I International Scientific and Practical Conference. 2017. P. 93-98.

[12] D. R. Kagirova, L.K. Orlik. Adaptive approach to estimating the average correlation properties of two time series, In the collection: Economic Forecasting: Models and Methods. Materials of the XII International Scientific and Practical Conference. 2016. P. 20-25.

[13] G. S. Zhukova, D. R. Kagirova. Adaptive approach to the analysis of correlation properties of financial time series, In the collection: Proceedings of 2018 11th International Conference "Management of Large-Scale System Development", MLSD 20182018. C. 8551811 .

[14] R. Aloui, M. S. Aïssa, D. K. Nguyen. Conditional dependence structure between oil prices and exchange rates: a copula-GARCH approach, Journal of International Money and Finance. Vol. 32. 2013, № 1. P. 719-738.

[15] A. Abramov, A. Radygin, M. Chernova. Long-term portfolio investments: a new view on profitability and risks, Voprosy Ekonomiki.. Vol. 10. 2015. P .54-77.

of currency pairs based on r: ARIMA and the neural
of network model, Scientific-methodical electronic journal Concept. Vol. 39. 2017. P. 3581-3585. 